\title{
Bioequivalence of a Fixed Dose Combination of Desloratadine/Betametha- sone Tablets (Oradus Beta) in Healthy Human Volunteers
}

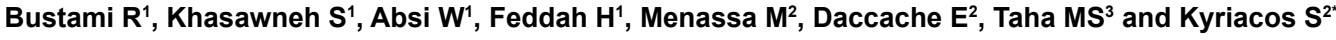 \\ ${ }^{1}$ Pharmaceutical Research Unit, Clinical Evaluation Centre, Amman, Jordan \\ ${ }^{2}$ Research and Development Department, Pharmaline, Jdeidet-El-Metn, Lebanon \\ ${ }^{3}$ Pharmacy Practice Department, School of Pharmacy, Lebanese American University, Byblos, Lebanon
}

\begin{abstract}
A fixed dose combination of desloratadine, a long-acting tricyclic antihistamine with selective peripheral histamine $\mathrm{H} 1$ receptor antagonistic activity, and betamethasone, a glucocorticoid, can potentially provide synergistic effect in the treatment of severe allergic conditions and improve clinical outcomes. Co-administration of an anti-allergy medication and a corticosteroid is extensively used in clinical practice, either as single drug tablets or as a fixed dose combination tablet. The current study was conducted to compare the pharmacokinetics of fixed combination tablets of desloratadine and betamethasone in 40 healthy human volunteers after a single oral dose in a randomized two-period, two-treatment, and two-sequence cross-over study. The study protocol was prepared in accordance to the requirements set in the EMA guidance for conducting bioequivalence studies. Reference (Frenaler Cort $5 \mathrm{mg}$ desloratadine $/ 0.6 \mathrm{mg}$ betamethasone film coated tablet, Roemmers S.A.I.C.F., Argentina) and test (Oradus $\beta 5 \mathrm{mg}$ desloratadine $/ 0.6 \mathrm{mg}$ betamethasone film coated tablet, Pharmaline, Lebanon) drugs were administered to fasted volunteers and blood samples were collected up to $72 \mathrm{~h}$ and assayed for desloratadine, hydroxydesloratadine metabolite and betamethasone using a validated LC-MS/MS method. The pharmacokinetic parameters AUC $\mathrm{C}_{0-\mathrm{t}}, \mathrm{C}_{\max }$, Tmax, T1/2, Ke, in addition to (for betamethasone only) $A \cup C_{0-\infty}$, MRTinf, and residual area (\%) were determined from plasma concentration-time profile by non-compartmental analysis method using thermos Scientific Kinetica (version 5.1). The analysis of variance did not show any significant difference between the two formulations and $90 \%$ confidence intervals fell within the acceptable range for bioequivalence $(80-125 \%)$. The resulting data demonstrated that when administered as fixed dose combination, the pharmacokinetics of desloratadine and betamethasone were bioequivalent and were well-tolerated.
\end{abstract}

Keywords: Desloratadine; Betamethasone; Pharmacokinetics; Bioequivalence

\section{Introduction}

Histamine plays a chief role in the pathogenesis of allergic disease, including allergic rhinitis (AR) and urticaria, predominantly through the H1-histamine receptor in target tissues. While AR represents a global health problem with an estimated worldwide prevalence of 10$25 \%$ and its prevalence is increasing [1], chronic idiopathic urticaria (CIU) has a major detrimental effect on quality of life that approximates that associated with chronic cardiac disease [2].

According to the American Academy of Otolaryngology-Head and Neck Surgery Foundation (AAO-HNSF) and the Allergic Rhinitis and its Impact on Asthma (ARIA) guidelines, oral second-generation antihistamines are strongly recommended for patients with AR and primary complaints of sneezing and itching [3,4]. If moderate to severe nasal and/or ocular symptoms are not controlled, a short course of oral glucocorticoids can be added [4]. For the management of CIU, second-generation antihistamines are the first-line treatment and may be titrated to 2-4 times their normal dose, if necessary. Systemic corticosteroids are frequently used for patients with refractory symptoms [5].

Co-administration of an antiallergy medication and a corticosteroid is extensively used in clinical practice, either as single drug tablets or as a fixed dose combination tablet. Such combination is indicated for the treatment of severe allergic conditions which require co-administration of an antiallergy medication and a corticosteroid. These conditions include: Atopic dermatitis, angioedema, urticaria, intermittent and persistent allergic rhinitis, allergic reactions due to food and medicines, allergic contact dermatitis and allergic processes involving the eye, such as allergic conjunctivitis.
The first generation H1-receptor antagonists, including chlorpheniramine and diphenhydramine, although effective in the management of allergic conditions, they are associated with undesirable CNS effects such as sedation and impaired psychomotor activity, and adverse anticholinergic effects [6,7]. Second generation H1-receptor antagonists (e.g., loratadine, desloratadine, cetirizine, levocetirizine, fexofenadine, azelastine) have superseded the first generation agents due to their favorable pharmacokinetics and negligible sedative and anticholinergic effects.

Desloratadine is a long-acting orally active major metabolite of loratadine, approved for the management of AR and CIU [8]. At a dose of $5 \mathrm{mg}$, it has a rapid onset of action (approximately $28 \mathrm{~min}$ ) as assessed in patients with seasonal AR [9]. According to the Biopharmaceutics classification system [10], desloratadine is a Class 1 drug as it exhibits a high solubility and high permeability [11]. It is rapidly absorbed after oral administration and the absorption is not affected by food [12,13]. The pharmacokinetics of the drug is linear in healthy volunteers over the dosage range 5-20 $\mathrm{mg}$ [14]. When normalized to $5 \mathrm{mg}$, maximum

*Corresponding author: Kyriacos S, R\&D Manager, Pharmaline, Jdeidet-ElMetn, Lebanon, Tel: 9619440 901; Fax: 9619448 418; E-mail: soulakyriacos@ maliagroup.com

Received July 22, 2016; Accepted August 19, 2016; Published August 30, 2016

Citation: Bustami R, Khasawneh S, Absi W, Feddah H, Menassa M, et al. (2016) Bioequivalence of a Fixed Dose Combination of Desloratadine/Betamethasone Tablets (Oradus Beta) in Healthy Human Volunteers. J Bioequiv Availab 8: 233241. doi: $10.4172 / \mathrm{jbb} .1000301$

Copyright: (c) 2016 Bustami R, et al. This is an open-access article distributed under the terms of the Creative Commons Attribution License, which permits unrestricted use, distribution, and reproduction in any medium, provided the original author and source are credited. 
Citation: Bustami R, Khasawneh S, Absi W, Feddah H, Menassa M, et al. (2016) Bioequivalence of a Fixed Dose Combination of Desloratadine/ Betamethasone Tablets (Oradus Beta) in Healthy Human Volunteers. J Bioequiv Availab 8: 233-241. doi: 10.4172/jbb.1000301

plasma concentrations $\left(\mathrm{C}_{\max }\right)$ and the area under the concentrationtime curve (AUC) of desloratadine were $3.3 \mu \mathrm{g} / \mathrm{L}$ and $77.5 \mu \mathrm{g} / \mathrm{L} . \mathrm{h}$, respectively [14]. Desloratadine has a volume of distribution $\left(\mathrm{V}_{\mathrm{d}}\right)$ of approximately $49 \mathrm{~L} / \mathrm{kg}$ [15].

Desloratadine is extensively metabolized in the liver to its principal active metabolite, $3-\mathrm{OH}$ desloratadine, which is consequently inactivated by glucuronidation [12]. Recent studies have demonstrated that the conversion of desloratadine to $3-\mathrm{OH}$ desloratadine involves $\mathrm{N}$-glucuronidation of desloratadine by UGT2B10, followed by 3-hydroxylation of the $\mathrm{N}$-glucuronide by CYP2C8 and its subsequent rapid hydrolysis [16,17].

In healthy volunteers, the drug's terminal phase half-life after a single 5-20 mg dose was 21.2-24.1 h [18]. Phenotypic polymorphism in the metabolism of desloratadine which significantly increase desloratadine half-life was identified. Genetically determined poor metabolizers of desloratadine were found to have a general population frequency of $6 \%$ and were most frequent in the African-American population (17\%) compared with Caucasian (2\%), Native-American (8\%), Hispanic (2\%), and Jordanian populations (3\%) [19,20]. No major cytochrome $\mathrm{P} 450$ inhibition has been reported with desloratadine and its bioavailability is minimally affected by drugs interfering with transporter molecules $[21,22]$.

Desloratadine has a higher $\mathrm{H} 1$ receptor affinity and avidity than other second-generation antihistamines [23]. It is 15-20 times more potent than loratadine and terfenadine, and has 50-194 times greater affinity than cetirizine, loratadine and fexofenadine [24,25].

Betamethasone is a potent glucocorticoid with anti-inflammatory and immunosuppressive properties. It can be administered orally (usual dose $0.6-7.2 \mathrm{mg}$ ), parentally, by local injection, by inhalation, or applied topically for the management of various disorders in which corticosteroids are indicated [26]. It has minimal to no mineralocorticoid activity and is commonly used to control severe or incapacitating allergic conditions intractable to adequate trials of conventional treatment and control of acute manifestations.

The pharmacokinetics after oral administration of betamethasone is hardly documented. According to the Biopharmaceutics Classification System, betamethasone is a Class 2 drug as it exhibits low solubility and high permeability [27]. It is metabolized in most tissues, but mainly in the liver, to inactive compounds and is cleared mainly by the liver, with a small amount excreted by the kidney [28]. It is $64 \%$ bound to plasma proteins and has a half-life of $6.5 \mathrm{~h} \mathrm{[29].}$

This bioequivalence study was performed using an in vivo method where the concentrations of the active ingredient and metabolite in an accessible biological fluid are measured as a function of time in humans. According to EMA, this is the most recommended method to assure that formulations perform in an equivalent manner and thus demonstrate that they are therapeutic equivalent [30].

Inter-subject pharmacokinetic variability for desloratadine and betamethasone is about $19 \%$ and $16 \%$ for $\mathrm{C}_{\max }$ respectively. Multiple dose pharmacokinetics are predictable from single-dose data [14,29].

\section{Objectives}

This study was conducted to assess the bioequivalence of a fixed dose combination (FDC) including desloratadine and betamethasone (Oradus Beta $5 \mathrm{mg}$ desloratadine/ $0.6 \mathrm{mg}$ betamethasone film coated tablet, Pharmaline, Lebanon) with a reference product (Frenaler Cort 5 mg desloratadine/ $0.6 \mathrm{mg}$ betamethasone film coated tablet, Roemmers S.A.I.C.F., Argentina). The study protocol was prepared with relevance to the requirements set in the EMA CPMP (CPMP/EWP/QWP/1401/98 Rev. 1 [30]. guidance for conduction of bioequivalence studies.

\section{Materials and Methods}

\section{Study products}

Investigational product: Oradus Beta $5 \mathrm{mg}$ desloratadine/0.6 mg betamethasone film coated tablet.

Batch no.: OB 22.1 Expiry Date: January/2016

\section{Manufacturer: Pharmaline, Lebanon}

Reference product: Frenaler Cort $5 \mathrm{mg}$ desloratadine $/ 0.6 \mathrm{mg}$ betamethasone film coated tablet

Batch no.: 00075 Expiry Date: July/2015

Manufacturer: Roemmers S.A.I.C.F., Argentina

\section{Study design}

Forty healthy, Caucasian adult males participated in this comparative study at PRU, Amman, Jordan. Although the study targeted, as per the protocol inclusion criteria, the general population, no female showed up at the site. The sample size was based on $19 \%$ intra-subject variability of Desloratadine at $\mathrm{C}_{\max }$ and $80 \%$ power to detect $10 \%$ difference between the two formulations [31,32]: 32 subjects would be sufficient; however since there is no published studies for betamethasone tablet, sample size was increased to 40 subjects. The mean age was $29 \pm 8$ years with a range of 18 to 49 years old, mean body weight was $71 \pm 10 \mathrm{~kg}$ with a range of $55-92 \mathrm{~kg}$, mean body height was $173 \pm 6 \mathrm{~cm}$ with a range of $162-190 \mathrm{~cm}$ and body mass index was $23.5 \pm 3.0 \mathrm{~kg} / \mathrm{m}^{2}$ with a range of $18.7-29.8 \mathrm{~kg} / \mathrm{m}^{2}$. The volunteers had medical history and physical examination within the range of clinical acceptability, and laboratory results (hematology, blood biochemistry, and urine analysis) within normal ranges. All subjects were instructed to abstain from taking vitamins and herbal supplements as well as grapefruit or grapefruit containing products for 7 days prior to first dosing and during the study period. In addition, subjects were instructed to abstain from taking drugs during the two weeks prior to study initiation day, and to abstain from taking enzyme stimulating or inhibiting drugs (e.g. Barbiturates, Carbamazepine, Phenytoin, Amphetamine, Benzodiazepine, cannabinoid, cocaine, opiates, phencyclidine and methadone) during one month before the study initiation.

Subjects were informed about the aim and risks of the study by the clinical investigator and then signed a written informed consent statement before entering the study. The study was carried out in accordance with the principles enunciated in the Declaration of Helsinki resolved in Helsinki in 1964 and amended in Seoul, 2008 [33], the ICH E6 harmonized tripartite guideline regarding Good Clinical Practice [34], CPMP Guideline on the Investigation of Bioequivalence [30], OECD Principles of Good Laboratory practices [35] and with recommendations published in "bio-international, bioavailability, bioequivalence, and pharmacokinetics [36] as well as with the local requirements of the Jordan Food and Drug Administration in relation to human rights and confidentiality [37]. Before the start of the study, the protocol was approved by the Institutional Review Board (IRB) of PRU, Amman, Jordan. 
Citation: Bustami R, Khasawneh S, Absi W, Feddah H, Menassa M, et al. (2016) Bioequivalence of a Fixed Dose Combination of Desloratadine/ Betamethasone Tablets (Oradus Beta) in Healthy Human Volunteers. J Bioequiv Availab 8: 233-241. doi: 10.4172/jbb.1000301

\section{Drug administration and sample collection}

The study was designed as an open-label, randomized, single dose, two-treatments, two-sequences, two-periods, and crossover design performed under fasting conditions.

Each period lasted $72 \mathrm{~h}$. The two periods were separated from each other by a washout period of 14 days. Subjects were admitted to PRU clinical site 12-18 h prior to study drug administration, until 24 $\mathrm{h}$ after dosing in each period. The subjects returned to the site to give the $36.00 \mathrm{~h}$ and remaining samples as per schedules time. Following an overnight fasting of at least $10 \mathrm{~h}$, the study subjects were given single dose of either formulations (reference or test) of desloratadine $5 \mathrm{mg}$ or betamethasone $0.6 \mathrm{mg}$ with $240 \mathrm{ml}$ of water. No food was allowed until $4 \mathrm{~h}$ after dose administration. Lunch and dinner were given to all volunteers according to a time schedule. There was no restriction on water intake $2 \mathrm{~h}$ after dosing. The volunteers were continuously monitored throughout the confinement period of study. They were not permitted to lie down or sleep for the first four hours after the dose. Blood samples were collected in each study period before $(1.00 \mathrm{~h} /$ predose) and at $00.33,0.66,1.00,1.33,1.66,2.00,2.50,3.00,3.50,4.00$, $4.50,5.00,6.00,8.00,10.00,12.00,15.00,20.00,24.00,36.00,48.00$ and $72.00 \mathrm{~h}$ after dosing. For each sample, $8 \mathrm{ml}$ of blood for desloratadine and betamethasone assay were drawn into heparinated tubes through indwelling cannula. Blood samples were centrifuged at $4000 \mathrm{rpm}$ for 5 minutes. The resulting plasma was immediately stored at $-70^{\circ} \mathrm{C}$ until assayed. After a washout period of 14 days the study was repeated in the same manner to complete the crossover design.

\section{Analysis for parent drugs}

Desloratadine: Desloratadine and the internal standards $\left(\left[{ }^{2} \mathrm{H}_{4}\right]-\right.$ Descarboethoxyloratadine) were extracted from human plasma samples by liquid-liquid extraction using (70:30) (V/V) (DEE:DCM). Prior to the extraction, 100 microliters of internal standard solution $(16.632 \mathrm{ng} / \mathrm{mL})$ were added to $1.00 \mathrm{ml}$ of plasma sample and vortexed for 30 seconds. Then $200 \mu \mathrm{L}$ of $0.1 \mathrm{M}$ sodium hydroxide was added to the sample which was subjected to vortex for 30 seconds followed by adding $5.00 \mathrm{ml}$ of (70:30) (V/V) (DEE:DCM). The sample then was subjected for 10 minutes mixing, then it was centrifuged (4000 rpm, 5 minutes); decantation of $3 \mathrm{~mL}$ of the supernatant layer was taken and then evaporated under nitrogen for 10 minutes and then sample was reconstituted with $200 \mu \mathrm{L}$ with mobile phase. $30 \mu \mathrm{L}$ then were injected to the column.

Analysis was performed using a method fully developed and validated at PRU Bio-analytical laboratory. The study plasma samples were analyzed using a validated LC coupled with MS-MS detector. All solvents used were of HPLC grade. Acetonitrile, 2-Propanol, DCM and Methanol were purchased from Scharlau (Spain). DEE was purchased from RCI labscan (Thailand), ammonium formate from JHD (China) and sodium hydroxide from Merck (Germany). Desloratadine was obtained from Pharmaline whereas the internal standard $\left(\left[{ }^{2} \mathrm{H}_{4}\right]-\right.$ Descarboethoxyloratadine) was from AlSAChim (France).

TheLC-MS-MS consisted of liquid chromatographic system (Agilent 1100 , Germany), coupled with a triple quadrupole spectrometer (API 5000) from Applied Biosystems, (MDS Sciex, Canada), equipped with ESI source for the ionization (positive ionization mode). Integration was done using the Analyst 1.5.1 software (Applied Biosystems).

Chromatographic separation for desloratadine was performed using Thermo Hypurity C18 $(5 \mu \mathrm{m})(150 \times 2.1 \mathrm{~mm})$ column from Thermo Scientific (USA). The mobile phase consisted of Solution A
(250 $\mathrm{ml}$ of $0.01 \mathrm{M}$ Ammonium formate, measured $\mathrm{pH}: 7.60 \pm 0.30)$ and Solution B (60:40, (V/V) MEOH: ACN) mixture (30:70) (V/V) and eluted at a rate of $0.300(\mathrm{~mL} / \mathrm{min})$. A flushing solution including methanol, acetonitrile, 2-propanol and water mixture (30:20:20:30) was used. The column temperature was $40^{\circ} \mathrm{C}$. Detection was done by multi reaction monitoring (MRM) mode, using the positive mode. The ion transition $(\mathrm{m} / \mathrm{z})$ for desloratadine was: $311.311 / 259.300$. The ion transition for the internal standard was: $315.263 / 263.00$. The peak area was measured, and the peak area ratio of drug to internal standard and the concentration were calculated by Analyst software.

Method development and validation were conducted in accordance with international guideline [38]. Under the described conditions, the lower limit of quantitation from $1000 \mu \mathrm{l}$ plasma was $0.060 \mathrm{ng} / \mathrm{ml}$ for desloratadine. Linearity was evaluated by calculating the linear regression (product moment correlation coefficient, $r$ ), and by evaluating the back calculated concentrations of the calibration standards. Results of the calibration curve linearity are summarized in Table 1a.

The relationship between concentration and peak area ratio was found to be linear within the range of $0.060-3.592 \mathrm{ng} / \mathrm{ml}$ for desloratadine. Accuracy and precision were verified using quality control samples at low, medium, high concentration as well as at the LLOQ. Results are reported in Table 1a.

The intra-day accuracy of the method for desloratadine ranged from 96.67 to $109.95 \%$, while the intra-day precision ranged from 1.51 to $9.68 \%$. The inter-day accuracy for desloratadine ranged from 99.44 to $110.58 \%$ while the inter-day precision ranged from 2.54 to $15.15 \%$. Absolute recovery - percentage ratio of the concentrations in an extracted plasma sample with the reference sample of the same concentration which was dissolved in the same solution as extracted sample-was between 89.20 and $90.52 \%$ for desloratadine. Accuracy ranged between $86.43 \%$ and $90.52 \%$. Short-term temperature stability study demonstrates that desloratadine is stable in plasma for $24 \mathrm{~h}$ on the bench at room temperature, as shown in Tables 1a and $1 \mathrm{~b}$. In addition, long term stability studies showed that desloratadine in the plasma samples were stable when stored frozen for up to 89 days at freezer of temperature range between $25^{\circ} \mathrm{C}$ to $-15^{\circ} \mathrm{C}$ and for up to 54 days between $-80^{\circ} \mathrm{C}$ to $-60^{\circ} \mathrm{C}$-Freeze and thaw stability test was determined after five cycles: After storage at temperature range of $-80^{\circ} \mathrm{C}$ to $-60^{\circ} \mathrm{C}$ and $-25^{\circ} \mathrm{C}$ to $-15^{\circ} \mathrm{C}$ for at least $12 \mathrm{~h}$ (or $24 \mathrm{~h}$ for the first cycle), samples were completely thawed unassisted at room temperature. The stability results indicate that desloratadine is stable under fifth freezing and thawing cycles at both temperature ranges. Table $1 \mathrm{a}$ and $1 \mathrm{~b}$ report the results after storage at temperature range of $-80^{\circ} \mathrm{C}$ to $-60^{\circ} \mathrm{C}$.

Hydroxydesloratadine: Although bioequivalence acceptance criteria were only based on parent compound pharmacokinetic parameters, assessing desloratadine metabolite data was done as supportive evidence of comparable therapeutic outcome.

Analysis was performed using a method fully developed and validated at PRU Bio-analytical laboratory. The analytical method is similar to the one described for desloratadine. 3-Hydroxydesloratadine and the internal standard (3-hydroxydesloratadine-d4) were obtained from TRC (Canada). Chromatographic detection was done by multi reaction monitoring (MRM) mode, using the positive mode. The ion transition $(\mathrm{m} / \mathrm{z})$ for hydroxydesloratadine was: $327.211 / 275.200$. The ion transition for the internal standard $\left(\left[{ }^{2} \mathrm{H}_{4}\right]\right.$-Descarboethoxyloratadine) was: $331.267 / 279.300$. The peak area was measured, and the peak area ratio of drug to internal standard and the concentration were calculated by Analyst software. 
Citation: Bustami R, Khasawneh S, Absi W, Feddah H, Menassa M, et al. (2016) Bioequivalence of a Fixed Dose Combination of Desloratadine/ Betamethasone Tablets (Oradus Beta) in Healthy Human Volunteers. J Bioequiv Availab 8: 233-241. doi: 10.4172/jbb.1000301

Method development and validation were conducted in accordance with international guideline $[35,36]$. Under the described conditions, the lower limit of quantitation from $1000 \mu \mathrm{l}$ plasma was $0.068 \mathrm{ng} / \mathrm{ml}$ for hydroxydesloratadine. Linearity was evaluated by calculating the linear regression (product moment correlation coefficient, $r$ ), and by evaluating the back calculated concentrations of the calibration standards. Results of the calibration curve linearity are summarized in Table $1 b$.

The relationship between concentration and peak area ratio was found to be linear within the range of $0.068-1.355 \mathrm{ng} / \mathrm{ml}$ for hydroxydesloratadine. Accuracy and precision were verified using quality control samples at low, medium, high concentration as well as at the LLOQ. Results are reported in Table $1 \mathrm{~b}$.

The intra-day accuracy of the method for hydroxydesloratadine ranged from 98.52 to $115.10 \%$, while the intra-day precision ranged from 1.72 to $7.14 \%$. The inter-day accuracy for hydroxydesloratadine ranged from 100.49 to $111.65 \%$ while the inter-day precision ranged from 3.20 to $8.11 \%$. Absolute recovery-percentage ratio of the concentrations in an extracted plasma sample with the reference sample of the same concentration which was dissolved in the same solution as extracted sample - was between 99.85 and $114.55 \%$ for hydroxydesloratadine. Accuracy ranged between $99.85 \%$ and $114.55 \%$. Short-term temperature stability study demonstrates that hydroxydesloratadine is stable in plasma for $24 \mathrm{~h}$ on the bench at room temperature, as shown in Tables $1 \mathrm{a}$ and $1 \mathrm{~b}$. In addition, long term stability studies showed that hydroxydesloratadine in the plasma samples were stable when stored frozen for up to 89 days at freezer of temperature range between $25^{\circ} \mathrm{C}$ to $15^{\circ} \mathrm{C}$ and for up to 54 days between $-80^{\circ} \mathrm{C}$ to $-60^{\circ} \mathrm{C}$. Freeze and thaw stability test was determined after five cycles: after storage at temperature range of $-80^{\circ} \mathrm{C}$ to $-60^{\circ} \mathrm{C}$ and $-25^{\circ} \mathrm{C}$ to $-15^{\circ} \mathrm{C}$ for at least $12 \mathrm{~h}$ (or $24 \mathrm{~h}$ for the first cycle), samples were completely thawed unassisted at room temperature. The stability results indicate that desloratadine is stable under fifth freezing and thawing cycles at both temperature ranges. Tables $1 \mathrm{a}$ and $1 \mathrm{~b}$ report the results after storage at temperature range of $-80^{\circ} \mathrm{C}$ to $-60^{\circ} \mathrm{C}$.

Betamethasone: Betamethasone and the internal standard $\left(\left[{ }^{2} \mathrm{H}_{5}\right]-\right.$ Betamethasone) were extracted from human plasma samples by liquidliquid extraction using (70:30) (V/V) (DEE:DCM).

Analysis was performed using a method fully developed and validated at PRU Bio-analytical laboratory. The analytical method used is similar to the one described for desloratadine. Betamethasone was obtained from Pharmaline whereas the internal standard $\left(\left[{ }^{2} \mathrm{H}_{5}\right]-\right.$ Betamethasone) was from AlsaChim (Canada). Chromatographic detection was done by multi reaction monitoring (MRM) mode, using the positive mode. The ion transition $(\mathrm{m} / \mathrm{z})$ for betamethasone was: 393.270/373.300. The ion transition for the internal standard was: $398.292 / 378.200$. The peak area was measured, and the peak area ratio of drug to internal standard and the concentration were calculated by Analyst software.

Method development and validation were conducted in accordance with international guideline [38]. Under the described conditions, the lower limit of quantitation from $1000 \mu \mathrm{l}$ plasma was $0.101 \mathrm{ng} / \mathrm{ml}$ for betamethasone. Linearity was evaluated by calculating the linear regression (product moment correlation coefficient, $r$ ), and by evaluating the back calculated concentrations of the calibration standards. Results of the calibration curve linearity are summarized in Table $1 \mathrm{c}$.

The relationship between concentration and peak area ratio was found to be linear within the range of $0.101-7.265 \mathrm{ng} / \mathrm{ml}$ for betamethasone. Accuracy and precision were verified using quality control samples at low, medium, high concentration as well as at the LLOQ. Results are reported in Table 1c.

The intra-day accuracy of the method for betamethasone ranged from 96.15 to $108.91 \%$, while the intra-day precision ranged from 6.01 to $13.64 \%$. The inter-day accuracy for betamethasone ranged from 98.62 to $111.34 \%$ while the inter-day precision ranged from 6.51 to $17.31 \%$. Absolute recovery-percentage ratio of the concentrations in an extracted plasma sample with the reference sample of the same concentration which was dissolved in the same solution as extracted sample-was between 94.31 and $101.26 \%$ for betamethasone. Accuracy ranged between $94.31 \%$ and $101.26 \%$. Short-term temperature stability study demonstrates that betamethasone is stable in plasma for $24 \mathrm{~h}$ on the bench at room temperature, as shown in Tables 1a and 1b. In addition, long term stability studies showed that betamethasone in the plasma samples were stable when stored frozen for up to 89 days at freezer of temperature range between $25^{\circ} \mathrm{C}$ to $-15^{\circ} \mathrm{C}$ and for up to 54 days between $-80^{\circ} \mathrm{C}$ to $-60^{\circ} \mathrm{C}$-Freeze and thaw stability test was determined after five cycles: After storage at temperature range of $-80^{\circ} \mathrm{C}$ to $-60^{\circ} \mathrm{C}$ and $-25^{\circ} \mathrm{C}$ to $-15^{\circ} \mathrm{C}$ for at least $12 \mathrm{~h}$ (or $24 \mathrm{~h}$ for the first cycle), samples were completely thawed unassisted at room temperature. The stability results indicate that betamethasone is stable under fifth freezing and thawing cycles at both temperature ranges. Table $1 \mathrm{a}$ and $1 \mathrm{~b}$ report the results after storage at temperature range of $-80^{\circ} \mathrm{C}$ to $-60^{\circ} \mathrm{C}$.

\section{Pharmacokinetic analysis}

Pharmacokinetic analysis was performed using the Thermo Scientific Kinetica (version 5.1) a commercially available Software package. (Thermo fisher, USA). The elimination rate constant (ke) was obtained as the slope of the linear regression of the log-transformed concentration values versus time data in the terminal phase. Elimination half-life $\left(\mathrm{T}_{1 / 2}\right)$ was calculated as $0.693 / \mathrm{ke}$. Area under the plasma concentration versus time curve $\left(\mathrm{AUC}_{0-\mathrm{t}}\right)$, from time $(0)$ to the last measurable concentration $(\mathrm{t})$, was calculated by the linear-up/logdown method. The area under the plasma concentration versus time curve from time (0) to infinity $\left(\mathrm{AUC}_{0-\infty}\right)$ is calculated as the sum of the $\mathrm{AUC}_{0-\mathrm{t}}$ plus the ratio of the last measurable plasma concentration to the elimination rate constant. The residual area was determined as the ratio of the difference in the two areas under the plasma concentration versus time curve over $\mathrm{AUC}_{0-\infty}$. The mean residual time from zero to infinity is calculated from the ratio of the area under the first moment curve to area under the plasma concentration versus time curve.

\section{Statistical analysis}

The pharmacokinetic parameters $\mathrm{AUC}_{0-\mathrm{t}}, \mathrm{AUC}_{0-\infty}$ and $\mathrm{C}_{\max }$ were considered as primary variables.

The following pharmacokinetic parameters of Desloratadine, its metabolite 3-hydroxydesloratadine and betamethasone were assessed: Maximum plasma concentration $\mathrm{C}_{\max }$, Time point of maximum plasma concentration $\mathrm{T}_{\max }$, Terminal elimination rate constant ke, Half-life of drug elimination during the terminal phase $\left(\mathrm{t}_{1 / 2}\right)$. In addition, Area under the plasma concentration-time curve from $0 \mathrm{~h}$ to $72 \mathrm{~h}\left(\mathrm{AUC}_{0 \rightarrow 72}\right)$ was evaluated for desloratadine and its metabolite 3-hydroxydesloratadine whereas Area under the plasma concentration-time curve from $0 \mathrm{~h}$ to the last quantifiable concentration estimate $\left(\mathrm{AUC}_{0 \rightarrow \text { last }}\right)$ and Area under the plasma concentration-time curve from $0 \mathrm{~h}$ to infinity $\left(\mathrm{AUC}_{0 \rightarrow \text { inf }}\right)$ were assessed for betamethasone as well as Residual area (\%) and mean residence time from $0 \mathrm{~h}$ to infinity. 
Citation: Bustami R, Khasawneh S, Absi W, Feddah H, Menassa M, et al. (2016) Bioequivalence of a Fixed Dose Combination of Desloratadine/ Betamethasone Tablets (Oradus Beta) in Healthy Human Volunteers. J Bioequiv Availab 8: 233-241. doi: 10.4172/jbb.1000301

\begin{tabular}{|c|c|c|c|c|c|c|c|c|c|c|}
\hline \multirow[t]{2}{*}{$\begin{array}{l}\text { Regression } \\
\text { equation }\end{array}$} & \multicolumn{2}{|c|}{$\begin{array}{l}\text { Concentration range } \\
\text { (ng/ml) }\end{array}$} & \multicolumn{2}{|c|}{ Number of points } & \multicolumn{2}{|c|}{ Correlation coefficient } & & & & \\
\hline & $0.060-3.592$ & & \multirow{2}{*}{\multicolumn{2}{|c|}{$0.180 \mathrm{ng} / \mathrm{ml}$}} & \multirow{2}{*}{\multicolumn{2}{|c|}{$\begin{array}{l}0.9971 \\
0.539 \mathrm{ng} / \mathrm{ml}\end{array}$}} & & & & \\
\hline \multirow[t]{2}{*}{ Plasma sample } & \multicolumn{2}{|l|}{$0.060 \mathrm{ng} / \mathrm{ml}$} & & & & & \multicolumn{2}{|l|}{$1.796 \mathrm{ng} / \mathrm{ml}$} & \multicolumn{2}{|l|}{$2.694 \mathrm{ng} / \mathrm{ml}$} \\
\hline & Accuracy $(\%)$ & Precision (\%) & Accuracy $(\%)$ & Precision (\%) & Accuracy $(\%)$ & Precision (\%) & Accuracy (\%) & Precision (\%) & Accuracy (\%) & Precision (\%) \\
\hline Intra-batch $(n=6)$ & 103.33 & 9.68 & 96.67 & 4.02 & 99.07 & 2.81 & 107.13 & 1.51 & 109.95 & 1.72 \\
\hline $\begin{array}{l}\text { Inter-batch } \\
(n=18)\end{array}$ & 110.00 & 15.15 & 102.78 & 8.11 & 99.44 & 3.54 & 109.58 & 2.54 & 110.58 & 4.90 \\
\hline $\begin{array}{l}\text { Short-term } \\
\text { stability }(n=6)\end{array}$ & - & - & 94.44 & 2.35 & - & - & - & - & 101.82 & 1.79 \\
\hline $\begin{array}{l}\text { Freeze and thaw } \\
\text { stability }(n=6)\end{array}$ & & - & 91.67 & 7.27 & - & - & - & - & 92.35 & 6.07 \\
\hline
\end{tabular}

1b 3-hydroxydesloratadine

\begin{tabular}{|c|c|c|c|c|c|c|c|c|c|c|}
\hline \multirow[t]{2}{*}{$\begin{array}{l}\text { Regression } \\
\text { equation }\end{array}$} & \multicolumn{2}{|c|}{$\begin{array}{l}\text { Concentration range } \\
\text { (ng/ml) }\end{array}$} & \multicolumn{2}{|c|}{ Number of points } & \multicolumn{2}{|c|}{ Correlation coefficient } & & & & \\
\hline & \multicolumn{2}{|l|}{$0.068-1.355$} & \multicolumn{2}{|l|}{8} & \multicolumn{2}{|l|}{0.9969} & & & & \\
\hline \multirow[t]{2}{*}{ Plasma sample } & \multicolumn{2}{|l|}{$0.068 \mathrm{ng} / \mathrm{ml}$} & \multicolumn{2}{|l|}{$0.203 \mathrm{ng} / \mathrm{ml}$} & \multicolumn{2}{|l|}{$0.405 \mathrm{ng} / \mathrm{ml}$} & \multicolumn{2}{|l|}{$0.675 \mathrm{ng} / \mathrm{ml}$} & \multicolumn{2}{|l|}{$1.013 \mathrm{ng} / \mathrm{ml}$} \\
\hline & Accuracy (\%) & Precision (\%) & Accuracy (\%) & Precision (\%) & Accuracy (\%) & Precision (\%) & Accuracy (\%) & Precision (\%) & Accuracy (\%) & Precision (\%) \\
\hline Intra-batch $(n=6)$ & 102.94 & 7.14 & 98.52 & 7.00 & 102.96 & 4.08 & 110.67 & 2.41 & 115.10 & 1.72 \\
\hline $\begin{array}{l}\text { Inter-batch } \\
(n=18)\end{array}$ & 108.82 & 8.11 & 100.49 & 7.35 & 103.46 & 5.97 & 110.96 & 3.20 & 111.65 & 7.07 \\
\hline $\begin{array}{l}\text { Short-term } \\
\text { stability }(n=6)\end{array}$ & - & - & 113.79 & 6.49 & - & - & - & - & 110.86 & 3.47 \\
\hline $\begin{array}{l}\text { Freeze and thaw } \\
\text { stability }(n=6)\end{array}$ & - & - & 106.90 & 5.07 & - & - & - & - & 103.36 & 9.26 \\
\hline
\end{tabular}

1c Betamethasone

\begin{tabular}{|c|c|c|c|c|c|c|c|c|c|c|}
\hline \multirow[t]{2}{*}{$\begin{array}{l}\text { Regression } \\
\text { equation }\end{array}$} & \multicolumn{2}{|c|}{$\begin{array}{l}\text { Concentration range } \\
\text { (ng/ml) }\end{array}$} & \multicolumn{2}{|c|}{ Number of points } & \multicolumn{2}{|c|}{ Correlation coefficient } & & & & \\
\hline & \multicolumn{2}{|l|}{$0.101-7.265$} & \multicolumn{2}{|l|}{8} & \multicolumn{2}{|l|}{0.9967} & & & & \\
\hline \multirow[t]{2}{*}{ Plasma sample } & \multicolumn{2}{|l|}{$0.101 \mathrm{ng} / \mathrm{ml}$} & \multicolumn{2}{|l|}{$0.303 \mathrm{ng} / \mathrm{ml}$} & \multicolumn{2}{|l|}{$1.090 \mathrm{ng} / \mathrm{ml}$} & \multicolumn{2}{|l|}{$3.632 \mathrm{ng} / \mathrm{ml}$} & \multicolumn{2}{|l|}{$5.449 \mathrm{ng} / \mathrm{ml}$} \\
\hline & Accuracy (\%) & Precision (\%) & Accuracy (\%) & Precision (\%) & Accuracy (\%) & Precision (\%) & Accuracy (\%) & Precision (\%) & Accuracy (\%) & Precision (\%) \\
\hline Intra-batch $(n=6)$ & 108.91 & 13.64 & 103.63 & 6.05 & 96.15 & 6.01 & 101.68 & 8.02 & 108.53 & 7.95 \\
\hline $\begin{array}{l}\text { Inter-batch } \\
(n=18)\end{array}$ & 102.97 & 17.31 & 108.25 & 11.28 & 98.62 & 6.51 & 108.54 & 7.56 & 111.34 & 7.83 \\
\hline $\begin{array}{l}\text { Short-term } \\
\text { stability }(n=6)\end{array}$ & - & - & 102.64 & 5.79 & - & - & - & - & 104.33 & 4.45 \\
\hline $\begin{array}{l}\text { Freeze and thaw } \\
\text { stability }(n=6)\end{array}$ & - & - & 104.95 & 4.09 & - & - & - & - & 102.24 & 8.96 \\
\hline
\end{tabular}

Table 1: Linearity, accuracy, precision and stability data for the analytical method validation for the determination of desloratadine (1a), 3-hydroxydesloratadine (1b) and betamethasone (1c) in plasma.

Two-way analysis of variance for crossover design was used to assess the effect of formulations, periods, sequences and subjects on these parameters. Difference between two related parameters was considered to be statistically significant for p-value equal to or less than 0.05. Parametric $90 \%$ confidence intervals based on the ANOVA of the mean test/reference $(\mathrm{T} / \mathrm{R})$ ratios of $\mathrm{AUCs}$ and $\mathrm{C}_{\max }$ were computed, [36] using SAS statistical package version 9.1.3, (SAS Institute Inc, USA). The data was transformed prior to analysis using a logarithmic transformation. $\mathrm{T}_{\max }$ adopted a non-parametric and was applied to untransformed data.

\section{Results and Discussion}

Out of the forty volunteers, thirty seven subjects completed the study and were evaluated for pharmacokinetic data for betamethasone. One subject was excluded by clinical investigator due to Tonsillitis and two other subjects withdrew freely of consent before admission in period II. Only thirty four subjects were evaluated for pharmacokinetic data for desloratadine as three subjects were excluded because their pre-dose concentration was greater than $5 \%$ of the $\mathrm{C}_{\max }$ Similarly, thirty four subjects were evaluated for pharmacokinetic data for hydroxydesloratadine metabolite as two subjects were excluded because their pre-dose concentration was greater than $5 \%$ of the $\mathrm{C}_{\max }$ and one subject was excluded because his reference AUC was less than $5 \%$ of reference medicinal product AUC geometric mean.

Desloratadine and betamethasone were well tolerated; unexpected incidents that could have influenced the outcome of the study did not occur. All volunteers were discharged in good health.

Both formulations were readily absorbed from the gastrointestinal tract. First quantifiable plasma concentrations of desloratadine, its metabolite and betamethasone were observed at $0.33 \mathrm{~h}$ : For desloratadine in 27 subjects after the test product administration and in 25 subjects after the reference product administration; for 3-hydroxydesloratadine in 15 subjects after the test product administration and in 7 subjects 
Citation: Bustami R, Khasawneh S, Absi W, Feddah H, Menassa M, et al. (2016) Bioequivalence of a Fixed Dose Combination of Desloratadine/ Betamethasone Tablets (Oradus Beta) in Healthy Human Volunteers. J Bioequiv Availab 8: 233-241. doi: 10.4172/jbb.1000301

after the reference product administration; for betamethasone in 31 subjects after the test product administration and in 24 subjects after the reference product administration.

The mean-concentration-time profiles for desloratadine, 3-hydroxydesloratadine and betamethasone for the two formulations are shown in Figures 1-3. Means of peak concentration of 2.053 and $2.098 \mathrm{ng} / \mathrm{ml}$ for desloratdine in test and reference products respectively were attained at means of 3.40 and $3.36 \mathrm{~h}$ after drug administration and then declined rapidly. Desloratadine exhibits two peaks plasma concentrations which may indicate that the drug undergoes enterohepatic circulation since desloratadine is a substrate for the efflux transporter P-glycoprotein. To our knowledge, this has not been reported in the literature. Desloratadine concentrations were quantifiable to $72.00 \mathrm{~h}$ in 33 subjects after the test product administration and to $72.00 \mathrm{~h}$ in 34 subjects after the reference product administration.

Means of peak concentration of 0.898 and $0.781 \mathrm{ng} / \mathrm{ml}$ for 3-hydroxydesloratadine were attained at means of 4.72 and $4.87 \mathrm{~h}$ after drug administration and then declined gradually. 3-hydroxydesloratadine concentrations were quantifiable to $72.00 \mathrm{~h}$ in 31 subjects after the test product administration and to $72.00 \mathrm{~h}$ in 31 subjects after the reference product administration.

Means of peak concentration of 5.128 and $4.912 \mathrm{ng} / \mathrm{ml}$ for Betamethasone were attained at means of 1.55 and $2.15 \mathrm{~h}$ after drug administration and then declined gradually. Betamethasone concentrations were quantifiable to $72.00 \mathrm{~h}$ in 5 subjects after the test product administration and to $72.00 \mathrm{~h}$ in 5 subjects after the reference product administration.

Tables 2a-2c report the pharmacokinetic parameters of desloratadine, its metabolite and betamethasone for the two brands which highlights the closeness of the results. Mean and standard deviation of the three pharmacokinetic parameters of the two formulations did not differ significantly.

For desloratadine, the relative bioavailability of Oradus Beta on the basis of Frenaler Cort is $96.29 \%$ (CV: 18.67\%) for $\mathrm{AUC}_{0-72}$ and $97.86 \%$ (CV: 15.71\%) for $\mathrm{C}_{\max }$. For desloratadine metabolite, the relative bioavailability of Oradus Beta on the basis of Frenaler Cort is $108.227 \%$
(CV: 16.52\%) for AUC0-72 and 114.381\% (CV: 18.34\%) for $\mathrm{C}_{\max }$. Data on the metabolite was used as supportive data only. For betamethasone, the relative bioavailability of Oradus Beta on the basis of Frenaler Cort is $99.92 \%(\mathrm{CV}: 13.76 \%)$ for $\mathrm{AUC}_{0-\mathrm{t}}, 100.00 \%$ (CV: $\left.13.83 \%\right)$ for $\mathrm{AUC}_{0 \text {. }}$ , and $104.51 \%(\mathrm{CV}: 11.30 \%)$ for $\mathrm{C}_{\text {max }}$. For bioequivalence assessment, the test and reference products are considered bioequivalent if the 90 $\%$ confidence interval of the geometric mean of the log-transformed data of the test/reference ratio percentage for desloratadine and for betamethasone fall within $80.00-125.00 \%$ for each of the primary end points. As reported in Table 3, confidence intervals for desloratadine primary pharmacokinetic parameters $\mathrm{C}_{\max }$, and $\mathrm{AUC}_{0-72}$ were 91.78$104.35 \%$, and $89.24-103.90 \%$ respectively. For betamethasone, $\mathrm{C}_{\max }$, $\mathrm{AUC}_{0-\mathrm{t}}$ and $\mathrm{AUC}_{0-\infty}$ values were 99.99-109.24\%, 94.69-105.45\% and 94.74-105.56\% respectively. For desloratadine metabolite, $\mathrm{C}_{\max }$ and $\mathrm{AUC}_{0-72}$ values were $106.14-123.26$ and $101.17-115.78 \%$ respectively. All values were all within the accepted $80-125 \%$ range.

Analysis of variance (ANOVA) for these parameters, after logtransformation of the data, reveals no statistically significant difference between the two formulations, with p-value greater than 0.05 . The ANOVA analysis of the drug demonstrates that the sequence, product and period effect for all bioequivalence metrics did not influence the outcome of the study.

The bioequivalence of Oradus Beta tablets vs. Frenaler tablets following a single dose administration of $5 \mathrm{mg}$ desloratadine and $0.6 \mathrm{mg}$ betamethasone to healthy adults under fast conditions was demonstrated.

\section{Conclusion}

The bioequivalence of Oradus $\beta$-desloratadine and betamethasone combination tablets-(Test Product/Pharmaline s.a.l, Lebanon) and Frenaler tablets (Reference Product/ Roemmers S.A.I.C.F., Argentina) following the administration of a single dose of $5 \mathrm{mg}$ desloratadine and $0.6 \mathrm{mg}$ betamethasone to healthy adults under fast conditions was demonstrated. Single dose of the FDC tablets was generally well tolerated. The two formulations tablet can be considered therapeutic equivalent, and thus they can be substituted for each other without any adjustment in dose or other additional therapeutic monitoring.
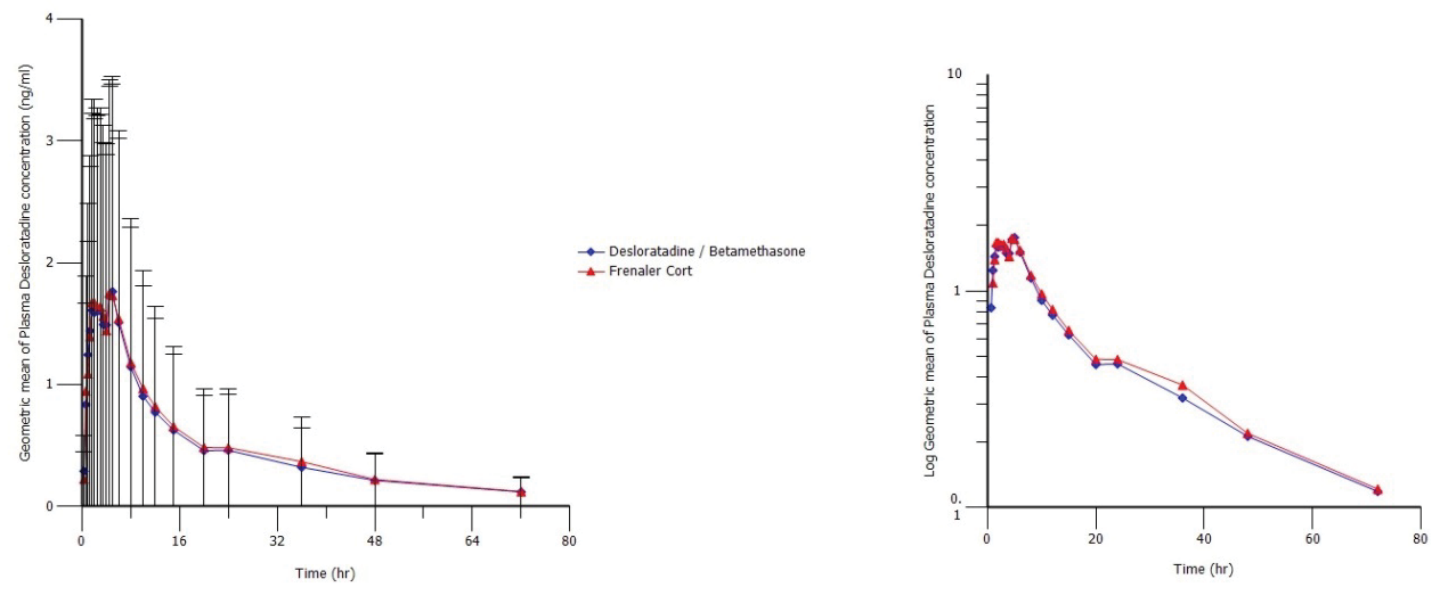

Figure 1: Geometric mean (SD) plasma concentration-time profiles for desloratadine following administration of FDC tablets Oradus Beta and Frenaler Cort tablets to 34 healthy human volunteers (Left: Arithmetic plot with error bars; Right: Semi-logarithmic plot). 
Citation: Bustami R, Khasawneh S, Absi W, Feddah H, Menassa M, et al. (2016) Bioequivalence of a Fixed Dose Combination of Desloratadine/ Betamethasone Tablets (Oradus Beta) in Healthy Human Volunteers. J Bioequiv Availab 8: 233-241. doi: 10.4172/jbb.1000301
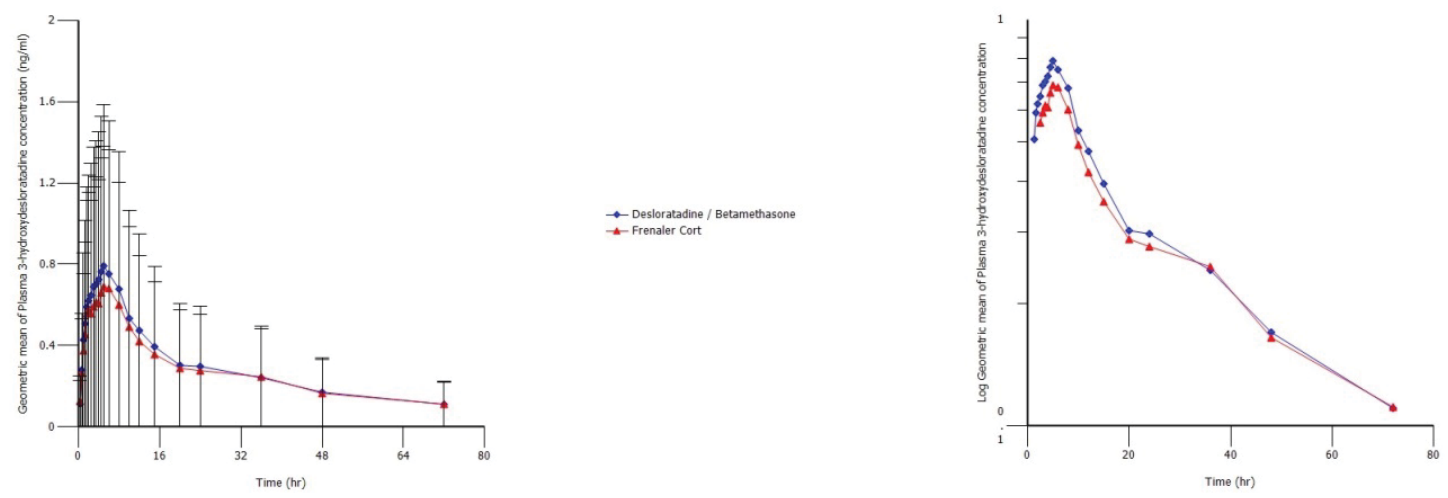

Figure 2: Geometric mean (SD) plasma concentration-time profiles for 3-hydroxydesloratadine following administration of FDC tablets Oradus Beta and Frenaler Cort tablets to 34 healthy human volunteers (Left: Arithmetic plot with error bars; Right: Semi-logarithmic plot).
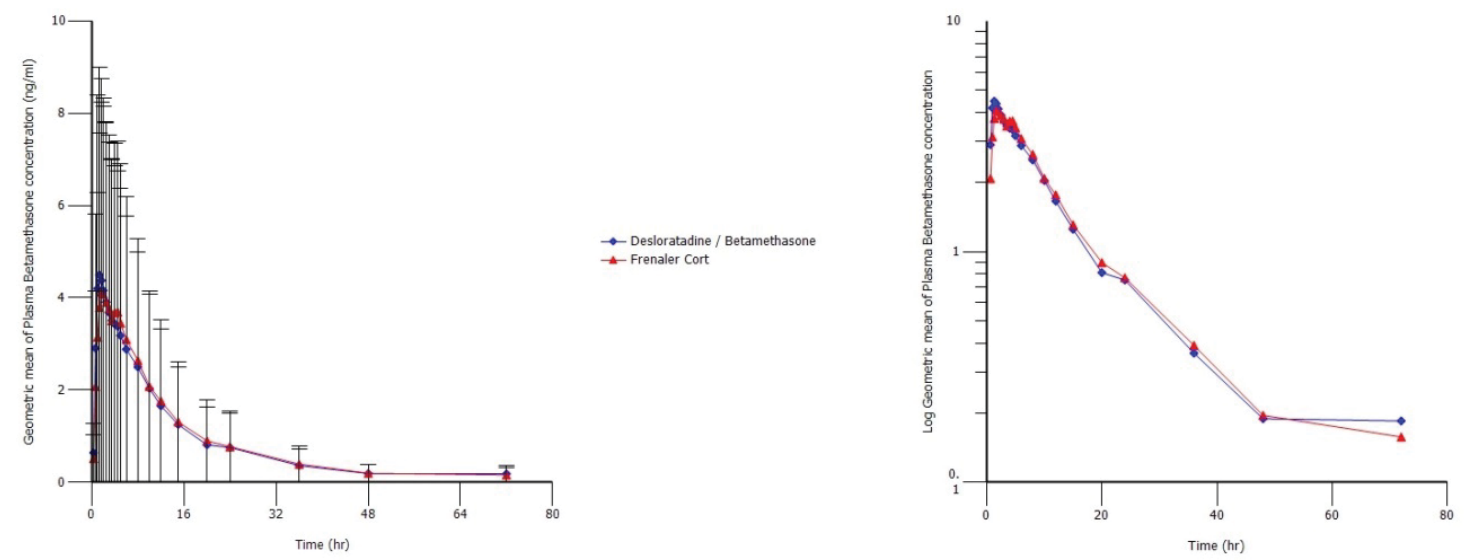

Figure 3: Geometric mean (SD) plasma concentration-time profiles for betamethasone following administration of FDC tablets Oradus Beta and Frenaler Cort tablets to 37 healthy human volunteers (Left: Arithmetic plot with error bars; Right: Semi-logarithmic plot).

2a Desloratadine $(n=34)$

\begin{tabular}{|c|c|c|}
\hline Pharmacokinetic Parameter & Oradus Beta 5 mg/0.6mg tablets (Test) & Frenaler Cort 5 mg/0.6mg tablets (Reference) \\
\hline $\mathrm{C}_{\text {max }}(\mathrm{ng} / \mathrm{ml})$ & $2.053 \pm 0.541$ & $2.098 \pm 0.563$ \\
\hline $\mathrm{AUC}_{0-\mathrm{t}}(\mathrm{ng} \times \mathrm{hr} / \mathrm{ml})$ & $34.128 \pm 9.707$ & $36.419 \pm 13.373$ \\
\hline $\mathrm{T}_{\max }(\mathrm{hr})$ & $3.40 \pm 1.65$ & $3.36 \pm 1.47$ \\
\hline
\end{tabular}

2b 3-hydroxydesloratadine $(n=34)$

\begin{tabular}{|c|c|c|}
\hline Pharmacokinetic Parameter & Oradus Beta $\mathbf{5 ~} \mathbf{~ g} / \mathbf{0 . 6} \mathbf{m g}$ tablets (Test) & Frenaler Cort $\mathbf{5 ~ m g / 0 . 6 m g ~ t a b l e t s ~ ( R e f e r e n c e ) ~}$ \\
\hline $\mathrm{C}_{\text {max }}(\mathrm{ng} / \mathrm{ml})$ & $0.898 \pm 0.309$ & $0.781 \pm 0.256$ \\
\hline $\mathrm{AUC}_{0-\mathrm{t}}(\mathrm{ng} \times \mathrm{hr} / \mathrm{ml})$ & $20.516 \pm 5.428$ & $19.232 \pm 5.740$ \\
\hline $\mathrm{T}_{\max }(\mathrm{hr})$ & $4.72 \pm 1.36$ & $4.87 \pm 1.93$ \\
\hline
\end{tabular}

2c Betamethasone ( $n=37)$

\begin{tabular}{|c|c|c|}
\hline Pharmacokinetic Parameter & Oradus Beta 5 mg/0.6mg tablets (Test) & Frenaler Cort 5 mg/0.6mg tablets (Reference) \\
\hline $\mathrm{C}_{\text {max }}(\mathrm{ng} / \mathrm{ml})$ & $5.128 \pm 0.950$ & $4.912 \pm 0.902$ \\
\hline $\mathrm{AUC}_{0-\mathrm{t}}(\mathrm{ng} \times \mathrm{hr} / \mathrm{ml})$ & $55.824 \pm 11.521$ & $56.742 \pm 15.928$ \\
\hline $\mathrm{AUC}_{0 .-\infty}(\mathrm{ng} \times \mathrm{hr} / \mathrm{ml})$ & $58.984 \pm 12.122$ & $59.882 \pm 17.169$ \\
\hline $\mathrm{T}_{\max }(\mathrm{hr})$ & $1.55 \pm 0.82$ & $2.15 \pm 1.12$ \\
\hline $\mathrm{T}_{1 / 2}(\mathrm{hr})$ & $11.12 \pm 3.89$ & $10.24 \pm 2.84$ \\
\hline $\mathrm{K}_{\text {elimination }}\left(\mathrm{hr}{ }^{-1}\right)$ & $0.0679 \pm 0.0180$ & $0.0723 \pm 0.0194$ \\
\hline $\mathrm{MRT}_{\text {inf }}(\mathrm{hr})$ & $15.21 \pm 4.22$ & $14.55 \pm 3.48$ \\
\hline Residual area $(\%)$ & $3.161 \pm 1.888$ & $3.140 \pm 1.925$ \\
\hline
\end{tabular}

Table 2: Pharmacokinetic parameters of desloratadine (2a), 3-hydroxydesloratadine (2b) and betamethasone (2c) for two brands (mean \pm standard deviation). 
Citation: Bustami R, Khasawneh S, Absi W, Feddah H, Menassa M, et al. (2016) Bioequivalence of a Fixed Dose Combination of Desloratadine/ Betamethasone Tablets (Oradus Beta) in Healthy Human Volunteers. J Bioequiv Availab 8: 233-241. doi: 10.4172/jbb.1000301

3a Desloratadine $(n=34)$

\begin{tabular}{|c|c|c|}
\hline Assessment Parameter & $\mathbf{C}_{\max }$ & AUC $_{0-72}$ \\
\hline Point Estimate (\%) & 97.86 & 96.29 \\
\hline Lower limit (\%) & 91.78 & 89.24 \\
\hline Upper limit (\%) & 104.35 & 103.90 \\
\hline Power & 99.98 & 99.17 \\
\hline
\end{tabular}

3b 3-hydroxydesloratadine $(n=34)$

\begin{tabular}{|c|c|c|}
\hline Assessment Parameter & $\mathbf{C}_{\max }$ & AUC $_{0-72}$ \\
\hline Point Estimate (\%) & 114.38 & 108.23 \\
\hline Lower limit (\%) & 106.14 & 101.17 \\
\hline Upper limit (\%) & 123.26 & 115.78 \\
\hline Power & 62.73 & 97.11 \\
\hline
\end{tabular}

3c Betamethasone $(n=37)$

\begin{tabular}{|c|c|c|c|}
\hline $\begin{array}{l}\text { Assessment } \\
\text { Parameter }\end{array}$ & $\mathbf{C}_{\max }$ & $\mathrm{AUC}_{0-\mathrm{t}}$ & $A U C_{0-\infty}$ \\
\hline Point Estimate (\%) & 104.51 & 99.92 & 100.00 \\
\hline Lower limit (\%) & 99.99 & 94.69 & 94.74 \\
\hline Upper limit (\%) & 109.24 & 105.45 & 105.56 \\
\hline Power & 99.10 & 99.10 & 99.10 \\
\hline
\end{tabular}

Table 3: Statistical Analysis: $90 \%$ confidence intervals of log transformed data of desloratadine (3a), 3-hydroxydesloratadine (3b) and betamethasone (3c).

\section{Acknowledgement}

Authors of the manuscript do not have conflict of interest to declare. The bioequivalence study was conducted by an independent contract research organization.

\section{References}

1. Bachert C, van Cauwenberge $P$, Khaltaev N, World Health Organization (2002) Allergic rhinitis and its impact on asthma. In collaboration with the World Health Organization. Executive summary of the workshop report. 7-10 December 1999, Geneva, Switzerland. Allergy 57: 841-855.

2. O'Donnell BF, Lawlor F, Simpson J, Morgan M, Greaves MW (1997) The impact of chronic urticaria on the quality of life. Br J Dermatol 136: 197-201.

3. Seidman MD, Gurgel RK, Lin SY, Schwartz SR, Baroody FM, et al. (2015) Clinical practice guideline: allergic rhinitis executive summary. Otolaryngol Head Neck Surg 152: 197-206

4. Brozek JL, Bousquet J, Baena-Cagnani CE, Bonini S, Canonica GW, et al. (2010) Global Allergy and Asthma European Network; Grading of Recommendations Assessment, Development and Evaluation Working Group. Allergic Rhinitis and its Impact on Asthma (ARIA) guidelines: 2010 revision. J Allergy Clin Immunol 126: 466-476.

5. Bernstein JA, Lang DM, Khan DA, Craig T, Dreyfus D, et al. (2014) The diagnosis and management of acute and chronic urticaria: 2014 update. J Allergy Clin Immunol 133: 1270-1277.

6. Handley DA, Magnetti A, Higgins AJ (1998) Therapeutic advantages of third generation antihistamines. Expert Opin Investig Drugs 7: 1045-1054.

7. Simons FE (1994) H1-receptor antagonists. Comparative tolerability and safety. Drug Saf 10: 350-380.

8. Murdoch D, Goa KL, Keam SJ (2003) Desloratadine: an update of its efficacy in the management of allergic disorders. Drugs 63: 2051-2077.

9. Horak F, Stübner P, Zieglmayer R, Kavina A (2000) Onset and duration of action of desloratadine after controlled pollen challenges in patients with seasonal allergic rhinitis. Allergy 63: 279.

10. Amidon GL, Lennernäs H, Shah VP, Crison JR (1995) A Theoretical Basis for a Biopharmaceutic Drug Classification: the Correlation of In Vitro Drug Product Dissolution and In Vivo Bioavailability. Pharm Res 12: 413-420.

11. Biopharmaceutics Classification System (BCS) (2014) Therapeutics Systems Research Laboratories. TSRL, Inc.

12. DuBuske LM (2002) Pharmacology of desloratadine: special characteristics. Clin Drug Invest 2: 1-11.
13. Gupta S, Banfield C, Affrime M, Marbury T, Padhi D, et al. (2002) Oral bioavailability of desloratadine is unaffected by food. Clin Pharmacokinet 1: 7-12.

14. Herron JM, Padhi D, Affrime MB, Glue P, Gupta S, et al. (2000) Doseproportionality, linearity, and pharmacokinetics of desloratadine in healthy adults. J Allergy Clin Immunol 105: S385.

15. Molimard M, Diquet B, Benedetti MS (2004) Comparison of pharmacokinetics and metabolism of desloratadine, fexofenadine, levocetirizine and mizolastine in humans. Fundam Clin Pharmacol 18: 399-411.

16. Kazmi F, Barbara JE, Yerino P, Parkinson A (2015) A long-standing mystery solved: the formation of 3-hydroxydesloratadine is catalyzed by CYP2C8 but prior glucuronidation of desloratadine by UDP-glucuronosyltransferase 2B10 is an obligatory requirement. Drug Metab Dispos 43: 523-533.

17. Kazmi F, Yerino P, Barbara JE, Andrew Parkinson (2015) Furthe characterization of the metabolism of desloratadine and its cytochrome P450 and UDP-glucuronosyltransferase (UGT) inhibition potential: Identification of desloratadine as a selective UGT2B10 inhibitor. Drug Metab Dispos 43: 1294 1302.

18. Gupta S, Banfield C, Affrime M, Marco A, Cayen M, et al. (2002) Desloratadine demonstrates dose proportionality in healthy adults after single doses. Clin Pharmacokinet 41: 1-6.

19. Prenner B, Kim K, Gupta S, Khalilieh S, Kantesaria B, et al. (2006) Adult and paediatric poor metabolisers of desloratadine: an assessment of pharmacokinetics and safety. Expert Opin Drug Saf 5: 211-223.

20. Hakooz N, Salem II (2012) Prevalence of desloratadine poor metabolizer phenotype in healthy Jordanian males. Biopharm Drug Dispos 33: 15-21.

21. Barecki ME, Casciano CN, Johnson WW, Clement RP (2001) In vitro characterization of the inhibition profile of loratadine, desloratadine, and $3-\mathrm{OH}$ desloratadine for five human cytochrome P-450 enzymes. Drug Metab Dispos 29: 1173-1175.

22. Wang EJ, Casciano CN, Clement RP, Johnson WW (2001) Evaluation of the interaction of loratadine and desloratadine with P-glycoprotein. Drug Metab Dispos 29: 1080-1083.

23. Devillier P, Roche N, Faisy C (2008) Clinical pharmacokinetics and pharmacodynamics of desloratadine, fexofenadine and levocetirizine: a comparative review. Clin Pharmacokinet 47: 217-230.

24. Kreutner W, Hey JA, Anthes J, Barnett A, Young S, et al. (2000) Preclinica pharmacology of desloratadine, a selective and nonsedating histamine $\mathrm{H} 1$ receptor antagonist. $1^{\text {st }}$ communication: receptor selectivity, antihistaminic activity, and antiallergenic effects. Arzneimittelforschung 50: 345-352.

25. Anthes JC, Gilchrest H, Richard C, Eckel S, Hesk D, et al. (2002) Biochemical characterization of desloratadine, a potent antagonist of the human histamine $\mathrm{H}$ (1) receptor. Eur J Pharmacol 449: 229-237.

26. Reynolds JEF, Lipman AG (2012) Intra-Agency Agreement between NICHD and the U.S. Food and Drug Administration (FDA) Oral Formulations PlatformReport 1. The Extra Pharmacopoeia (30 $30^{\text {th }}$ edn.) Martindale.

27. AHFS drug information (2006) Corticosteroids general statement. Bethesda American Society of Health-System Pharmacists pp: 2974-2987.

28. http://reference.medscape.com/drug/celestone-soluspanbetamethasone-342740\#10

29. Verbeeck RK, Musuamba FT (2012) The revised EMA guideline for the investigation of bioequivalence for immediate release oral formulations with systemic action. J Pharm Pharm Sci 15: 376-388.

30. Deng C, Graz J (2002) Generating Randomization Schedules Using SAS ${ }^{\circledR}$ Programming. Statistics and Data Analysis. SUGI 27: 267-272.

31. Diletti E, Hauschke D, Steinijans VW (1991) Sample size determination for bioequivalence assessment by means of confidence intervals. Int $\mathrm{J}$ Clin Pharmacol Ther Toxicol 29: 1-8.

32. (2008) Declaration of Helsinki" as amended in Seoul.

33. European Medicines Agency (2002) ICH Topic E6. Guidelines for Good Clinica Practice, Step 5. Note for Guidance on Good Clinical Practice. EMA, London.

34. Organisation for Economic Co-operation and Development (1998) OECD Series on Principles of Good Laboratory Practice and Compliance Monitoring, Number 1. OECD Principles of Good Laboratory Practice. OECD Environment Directorate, Paris. 
Citation: Bustami R, Khasawneh S, Absi W, Feddah H, Menassa M, et al. (2016) Bioequivalence of a Fixed Dose Combination of Desloratadine/ Betamethasone Tablets (Oradus Beta) in Healthy Human Volunteers. J Bioequiv Availab 8: 233-241. doi: 10.4172/jbb.1000301

35. Blume H, Midha K (1993) Bio-International 92, conference on bioavailability, bioequivalence, and pharmacokinetic studies. Eur J Drug Metab Pharmacokinet 18: $225-232$

36. (2011) FDA Clinical Studies Law no. 2 for the year.
37. European Medicines Agency (2009) Guideline on Bioanalytical Method Validation. EMEA, London.

38. Guidance of Industry; Bio-analytical Method Validation (2001) U.S. Department of Health and Human Services Food and Drug Administration pp: 1-22. 